\title{
A Comparative Study of Different Two-Phase Models for the Propane Oxidative Dehydrogenation in a Bubbling Fluidized Bed Containing $\mathrm{VO}_{\mathbf{x}} / \gamma-\mathrm{Al}_{2} \mathrm{O}_{3}$ Catalyst
}

\author{
Shayma A. Khraibet ${ }^{\mathrm{a}}$, Golshan Mazloom* ${ }^{\mathrm{a} *}$, Farhad Banisharif ${ }^{\mathrm{b}}$ \\ ${ }^{a}$ Department of Chemical Engineering, Faculty of Engineering, University of Mazandaran, \\ P. O. Box 47416-13534, Babolsar, Iran \\ ${ }^{b}$ School of Chemical, Petroleum and Gas Engineering, Iran University of Science and \\ Technology, P. O. Box 16846-13114, Narmak, Tehran, Iran
}

*Corresponding Author: G. Mazloom, golshanmazloom84@gmail.com 


\section{Section S1: Physical properties of catalysts}

The physical properties of the catalyst particles taken from ref. 1 are shown in Table S1.

Table S1: physical properties of catalyst particle ${ }^{1}$

\begin{tabular}{lll}
\hline Parameter & Symbol & Value \\
\hline Density of particle & $\rho_{s}$ & $2260 \mathrm{Kg} \cdot \mathrm{m}^{-3}$ \\
Diameter of particle & $d_{s}$ & $77 \mu \mathrm{m}$ \\
Minimum fluidization velocity & $\mathrm{U}_{\mathrm{mf}}$ & $0.0067 \mathrm{~m} \cdot \mathrm{s}^{-1}$
\end{tabular}

\section{Section S2: Minimum bubbling velocity}

Based on the physical properties of the catalyst (diameter and density presented in Table S1), the catalyst in this work is classified as Geldart A. It is notable that for Geldart A particles, there is an interval between the bed expansion and appearing of bubble structure ${ }^{2}$. The gas velocity where the bubbles appear is defined as the minimum bubble velocity $\left(\mathrm{U}_{\mathrm{mb}}\right)$. It was demonstrated that $U_{m b}$ was independent of the bed diameter and depended only on the solids and gas properties ${ }^{4,5}$. Using the computational fluid dynamics method, Wang et al. ${ }^{3}$ investigated the effect of particle and gas properties on the minimum bubbling velocity of Goldart A particles in fluidized bed reactor (figures 5, 6 and 7 of ref. 3).

Zaynali and Alavi investigated the ODHP in the fluidized bed reactor with superficial velocities in the range of $\mathrm{U}_{0} / \mathrm{U}_{\mathrm{mf}}=1.5$ to 3.5 which is higher than $\mathrm{U}_{\mathrm{mb}}$ predicted by Wang et al. ${ }^{3}$. 


\section{Section S3: Reaction network}

The nature of active species over the catalyst surface plays significant roles in determining the selectivity, mechanism and kinetics of the catalyst ${ }^{6}$. Based on the literature data, it has been proposed that propylene formation can be occurred over isolated vanadium species. While the polymeric $\mathrm{VO}_{\mathrm{x}}$ species are active for $\mathrm{CO}_{\mathrm{x}}$ formation ${ }^{6}$.

Therefore one important factor affecting the propylene selectivity is vanadium content ${ }^{7}$. Some studies ${ }^{8}$ showed that at low vanadium loading, a highly dispersed isolated $\mathrm{VO}_{4}$ surface species is formed. While with increasing vanadium loading, the species evolve from isolated to polymeric polyvanadates.

The fluidization models implemented in this study was validated against experimental data of Zaynali and Alavi ${ }^{1}$ over 2.7 wt.\% $\mathrm{V} / \gamma-\mathrm{Al}_{2} \mathrm{O}_{3}$. In another paper, Zaynali and Alavi ${ }^{9}$ have investigated the effects of vanadium content on the propylene and $\mathrm{CO}_{\mathrm{x}}$ selectivity. The results indicated that with increasing the vanadia content up to 9 wt.\%, the $\mathrm{CO}_{\mathrm{x}}$ selectivity increased significantly and the maximum propylene selectivity was obtained on the catalyst with 2.7 wt. \% of vanadia possibly due to the higher dispersion.

According to reasons explained and in order to simplify, the reaction scheme proposed by Routray et al. ${ }^{10}$ with only one path for $\mathrm{CO}_{\mathrm{x}}$ formation from propylene was selected in this work.

Since The $\mathrm{C}-\mathrm{H}$ bond in the methylene group of propane is significantly stronger than the allylic C-H bond of propylene leading to rapid over-oxidation of propylene ${ }^{2}$. Therefore, deep oxidation of propane can be neglected. 


\section{Section S4: Empirical correlations for hydrodynamic parameters}

Some of the hydrodynamic parameters were calculated by empirical correlations listed in Tables S2 and S3.

Table S2: Hydrodynamic parameters used in all STP, DTP and SH models 11,12

Parameter Empirical Equation

Bubble diameter

$$
\mathrm{d}_{\mathrm{b}}=0.21 \mathrm{H}^{0.8}\left(\mathrm{U}_{0}-\mathrm{U}_{\mathrm{mf}}\right)^{0.42} \exp \left[-0.25\left(\mathrm{U}_{0}-\mathrm{U}_{\mathrm{mf}}\right)^{2}-0.1\left(\mathrm{U}_{0}-\mathrm{U}_{\mathrm{mf}}\right)\right]
$$

(Mostoufi)

Bubble velocity

$$
\mathrm{U}_{\mathrm{b}}=\mathrm{U}_{0}-\mathrm{U}_{\mathrm{mf}}+\mathrm{u}_{\mathrm{br}}
$$

$$
\begin{aligned}
& \mathrm{U}_{\mathrm{br}}=0.711\left(\mathrm{gd}_{\mathrm{b}}\right)^{0.5} \\
& \frac{1}{\mathrm{~K}_{\mathrm{be}}}=\frac{1}{\mathrm{~K}_{\mathrm{bc}}}+\frac{1}{\mathrm{~K}_{\mathrm{ce}}}
\end{aligned}
$$

Bubble to emulsion

gas interchange

$$
\mathrm{K}_{\mathrm{bc}}=4.5\left(\frac{\mathrm{U}_{\mathrm{e}}}{\mathrm{d}_{\mathrm{b}}}\right)+5.85\left(\frac{\mathrm{D}_{\mathrm{AB}}^{0.5} \mathrm{~g}^{0.25}}{\mathrm{~d}_{\mathrm{b}}{ }^{1.25}}\right)
$$

coefficient

$$
\mathrm{K}_{\mathrm{ce}}=6.77 \sqrt{\left(\frac{\mathrm{D}_{\mathrm{AB}} \varepsilon_{\mathrm{e}} \mathrm{u}_{\mathrm{br}}}{\mathrm{d}_{\mathrm{b}}^{3}}\right)}
$$


Table S3: Hydrodynamic parameters used in all STP, DTP and SH models ${ }^{11,12}$.

\begin{tabular}{|c|c|c|}
\hline parameter & Equation & Type of model \\
\hline \multirow[b]{2}{*}{ Emulsion velocity } & $\mathrm{U}_{\mathrm{e}}=\frac{\mathrm{U}_{0}-\delta \mathrm{U}_{\mathrm{b}}}{1-\delta}$ & DTP \\
\hline & $\mathrm{U}_{\mathrm{e}}=\mathrm{U}_{\mathrm{mf}}$ & STP, SH \\
\hline \multirow{3}{*}{ Bubble fraction } & $\delta=1-\exp \left(-\frac{\mathrm{U}_{0}-\mathrm{U}_{\mathrm{mf}}}{0.62}\right)$ & \\
\hline & $\delta=\frac{\mathrm{U}_{0}-\mathrm{U}_{\mathrm{mf}}}{}$ & DTP \\
\hline & $\mathrm{O}-\overline{\mathrm{U}_{\mathrm{b}}-\mathrm{U}_{\mathrm{mf}}}$ & STP, SH \\
\hline \multirow{2}{*}{ Average bubble voidage } & $\varepsilon_{\mathrm{b}}=0.784-0.139 \exp \left(-\frac{\mathrm{U}_{0}-\mathrm{U}_{\mathrm{mf}}}{0.272}\right)$ & DTP \\
\hline & $\varepsilon_{\mathrm{b}}=1$ & STP, SH \\
\hline \multirow[b]{2}{*}{ Average emulsion voidage } & $\varepsilon_{\mathrm{e}}=\varepsilon_{\mathrm{mf}}+0.00061 \exp \left(\frac{\mathrm{U}_{0}-\mathrm{U}_{\mathrm{mf}}}{0.262}\right)$ & DTP \\
\hline & $\varepsilon_{\mathrm{e}}=\varepsilon_{\mathrm{mf}}$ & STP, SH \\
\hline Average bed voidage & $\varepsilon=(1-\delta) \varepsilon_{\mathrm{e}}+\delta \varepsilon_{\mathrm{b}}$ & DTP, STP, SH \\
\hline
\end{tabular}

\section{Section S5: Solution method}

The solution methods utilized for different models were shown in the flowcharts of figure S1, briefly. 


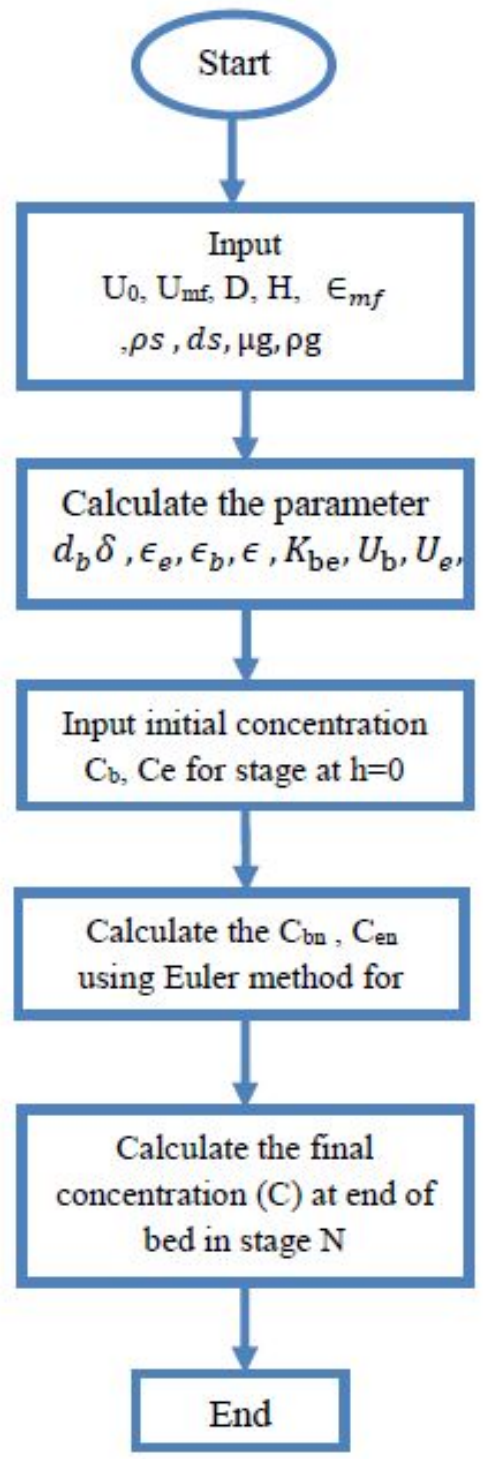

(a)

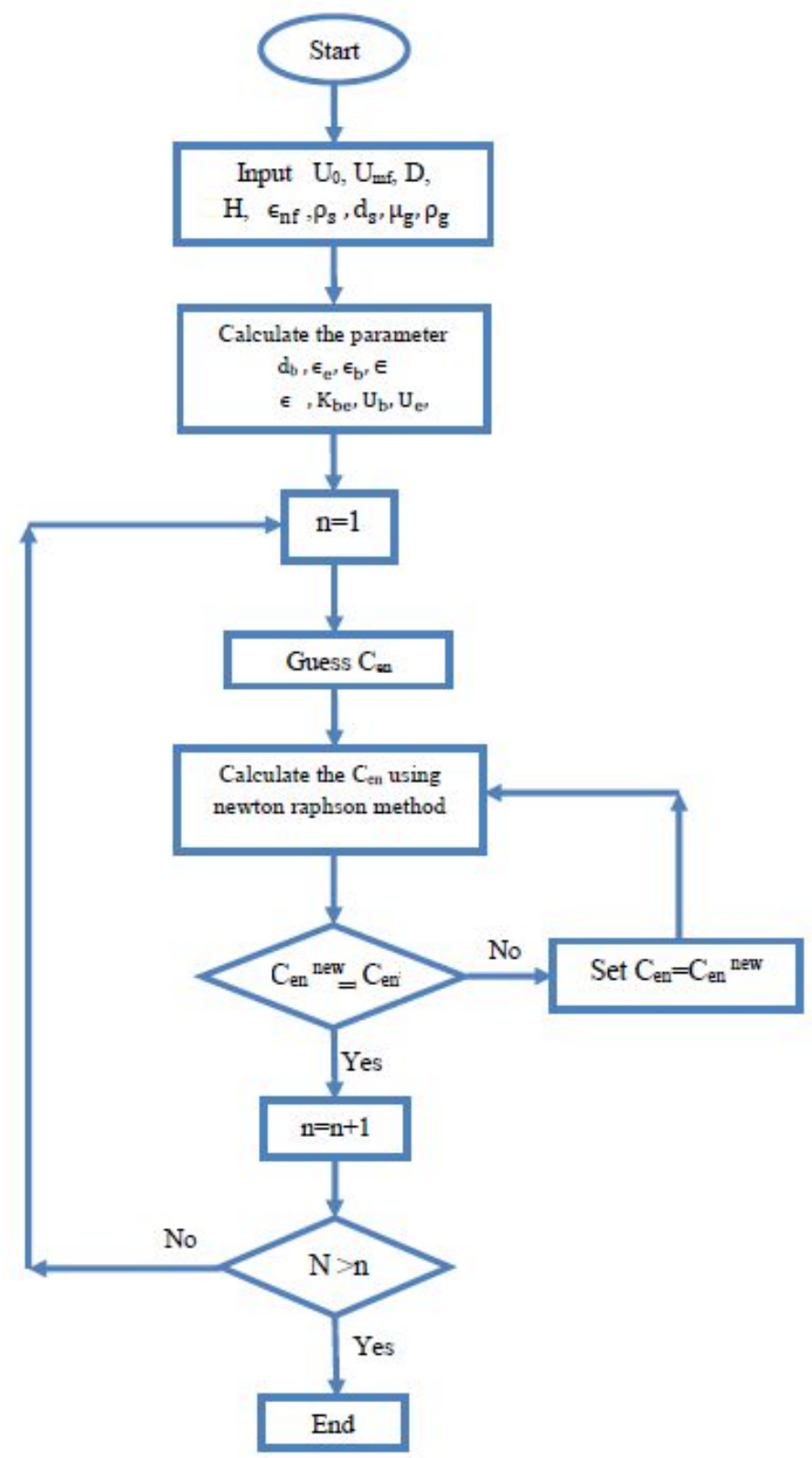

(b)

Figure S1: Method of Solution: (a) DTP and STP models, (b) SH model 


\section{Section S6: The performance of simple single phase CSTR model}

The fluidized bed reactor can be modeled by a simple single phase CSTR model. In this model, the solids are distributed uniformly in the bed with average voidage of $\varepsilon$ and the gas flowing through the bed is modeled as a CSTR reactor. The mole balance for specie A over the reactor volume is as Eq. $\mathrm{S} 1$ :

$U_{0}\left(C_{A 0}-C_{A}\right)+\rho_{S}(1-\varepsilon) R_{A} H=0$

Where $\mathrm{H}$ is the height of the reactor and average voidage of $\varepsilon$ is calculated as Eq. S2:

$$
\varepsilon=(1-\delta) \varepsilon_{\mathrm{e}}+\delta
$$

The propane conversion predicated by CSTR model at different $\mathrm{U}_{0} / \mathrm{U}_{\mathrm{mf}}$ is shown in Figure S2 and accompanied by other models results and experimental data. As seen, The CSTR model ability for prediction propane conversion is poor. It predicts lower propane conversion than the experimental data at all gas velocities. In addition, the conversions predicted by the CSTR model are much lower than the predicted values of the other models. However, as the $\mathrm{U}_{0}$ increases, the results of the CSTR model get closer to the others especially to the SH model.

In the two phase models (STP, DTP and SH models), at low $\mathrm{U}_{0}$, a small fraction of the total gas flows as bubbles, the progress of the reaction occurs only (STP and SH) and mostly (DTP) in the emulsion phase. Whereas, in the CSTR model, the reaction occurs in all the bed. Since the emulsion is more concentrated in catalyst rather than the average solids concentration in the bed, therefore the predicted reaction rates are higher in emulsion of two phase models than the CSTR.

There is an important factor in the two-phase models; the mass transfer from bubble to emulsion, that can affect the concentration profiles in fluidized beds. As shown in Figure 4 (NTU versus $\mathrm{U}_{0} / \mathrm{U}_{\mathrm{mf}}$ ), the overall mass transfer between bubble and emulsion is lower at higher gas velocities leading to decreasing concentrations of compounds as well as reaction 
rates in the emulsion phase. Therefore, the performance of the CSTR model becomes closer to the two phase models especially the $\mathrm{SH}$ model predictions which assumes that emulsion composes of a number of equivalent CSTR stages in series.

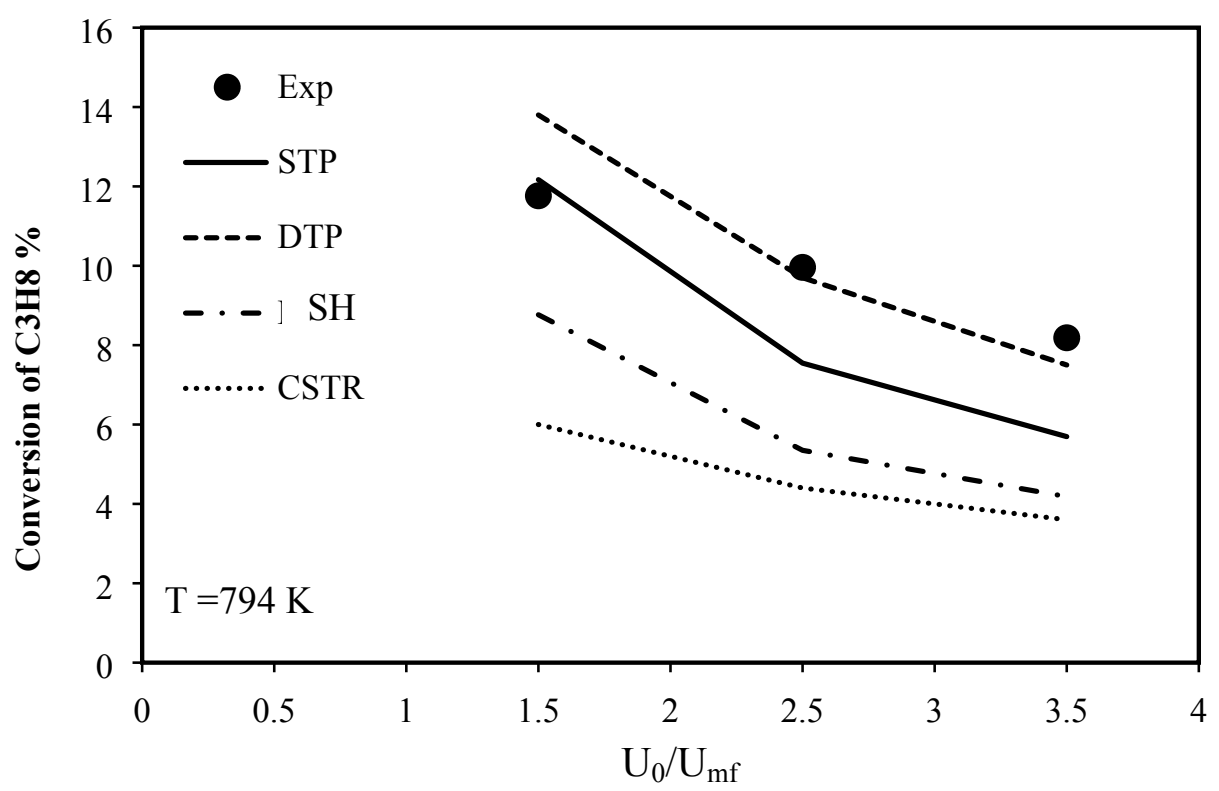

Figure S2: Prediction of propane conversion of the fluidized bed reactor by different hydrodynamic models at different superficial gas velocities at $794 \mathrm{~K}, \mathrm{C}_{0 \text {, propane }}=10 \% \mathrm{~mol}$, Molar ratio of feed composition: $\mathrm{C}_{3} \mathrm{H}_{8} / \mathrm{O}_{2} / \mathrm{N}_{2}: 1 / 1 /$ balanced.

\section{References}

(1) Zaynali, Y.; Alavi-Amleshi, S. M. Comparative Study of Propane Oxidative Dehydrogenation in Fluidized and Fixed Bed Reactor. Particul. Sci. Technol. 2017, 35(6), 667-673.

(2) Geldart, D.; Abrahamsen, A.R.; Homogeneous Fluidization of Fine Powders Using Various Gases and Pressures. Powder Technol. 1978, 19, 133-136. 
(3) Wang, J.; van der Hoef, M.A.; Kuipers, J.A.M. CFD Study of the Minimum Bubbling Velocity of Geldart A Particles In Gas-Fluidized Beds. Chem. Eng. Sci. 2010, 65(12), 37723785 .

(4) Rapagna, S.; Foscolo, P.U.; Gibilaro, L.G.; The Influence of Temperature on the Quality of Gas Fluidization. Int. J. Multiph. 1994, 20, 305-313.

(5) Simone, S.; Harriott, P.; Fluidization of Fine Powders with Air in The particulate and the Bubbling Regions. Powder Technol. 1984, 26, 161-167.

(6) Gambo, Y.; Adamu, S.; Abdulrasheed, A.A.; Lucky, R.A.; Ba-Shammakh, M.S.; Hossain, M.M. Catalyst Design and Tuning for Oxidative Dehydrogenation of Propane-A review. App. Catal. A Gen. 2020, 609, 117914.

(7) Michaels, J.N.; Stern, D.L.; Grasselli, R.K. Oxydehydrogenation of Propane over Mg-VSb-Oxide Catalysts. II. Reaction Kinetics and Mechanism. Catal. Lett. 1996, 42, 139-148.

(8) Rostom, S.; de Lasa, H.; Propane Oxidative Dehydrogenation on Vanadium-Based Catalysts under Oxygen-Free Atmospheres. Catal. 2020, 10(4), 418.

(9) Zaynali, Y.; Alavi, S. M. Higher Propene Yield by Tailoring Operating Conditions of Propane Oxidative Dehydrogenation Over $\mathrm{V}_{2} \mathrm{O}_{5} / \gamma-\mathrm{Al}_{2} \mathrm{O}_{3}$. J. Serbian Chem. Soc. 2015, 80(3), $355-366$.

(10) Routray, K.; Reddy, K.R.S.K.; Deo. G. Oxidative Dehydrogenation of Propane on $\mathrm{V}_{2} \mathrm{O}_{5} / \mathrm{Al}_{2} \mathrm{O}_{3}$ and $\mathrm{V}_{2} \mathrm{O}_{5} / \mathrm{TiO}_{2}$ Catalysts: Understanding the Effect of Support by Parameter Estimation. Appl. Catal. A Gen. 2004, 265(1), 103-113.

(11) Jafari, R.; Sotudeh-Gharebagh, R.; Mostoufi, N. Performance of the Wide-Ranging Models for Fluidized Bed Reactors. Adv. Powder Technol. 2004, 15(5), 533-548.

(12) Cui, H.; Mostoufi, N.; Chaouki, J. Characterization of Dynamic Gas-Solid Distribution in Fluidized Beds. Chem. Eng. J. 2000, 79(2), 133-143. 